IRA-International Journal of Technology \& Engineering ISSN 2455-4480

Proceedings of the

International Conference on Science \& Engineering for Sustainable Development (2017) Pg. no.257-265

Published by: Institute of Research Advances https://research-advances.org/index.php/IRAJTE

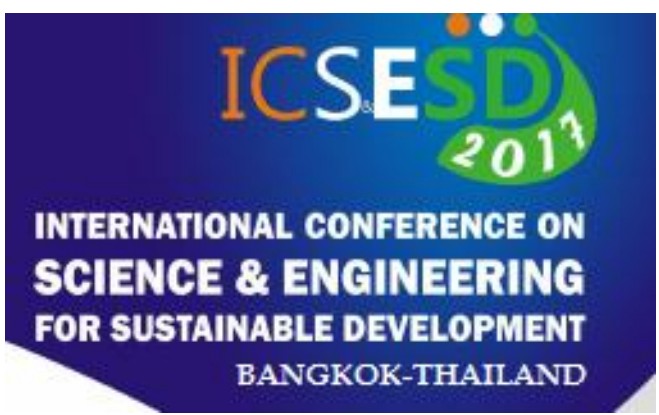

\title{
How to Accelerate Sustainability in Information Technology Sector
}

\author{
Vishakha Chande Nandanpawar \\ IT and Sustainability Professional, Postgraduate in Sustainable Business, \\ University of Cambridge, UK.
}

Type of Review: Originality Check \& Peer Review under the responsibility of the Scientific Committee of the Conference and The Institution of Engineers (India).

DOI: http://dx.doi.org/10.21013/jte.ICSESD201725

How to cite this paper:

Nandanpawar, V. (2017). How to Accelerate Sustainability in Information Technology Sector. Proceedings of the International Conference on Science \& Engineering for Sustainable Development (2017), 257-265. doi: http://dx.doi.org/10.21013/jte.ICSESD201725

(C) International Conference on Science \& Engineering for Sustainable Development\& The Institution of Engineers (India).

\section{(cc) BY-NC}

This work is licensed under a Creative Commons Attribution-Non Commercial 4.0 International License subject to proper citation to the publication source of the work.

Disclaimer: The conference papers as published by the Institute of Research Advances (IRA) are the views and opinions of their respective authors and are not the views or opinions of the IRA. The IRA disclaims of any harm or loss caused due to the published content to any party. 


\section{ABSTRACT}

In view of current economic and industrial growth, the whole world is facing various Sustainability challenges like Climate change and Global warming, energy management, food security, poverty, water scarcity and many more. To address these issues properly, it is necessary to mainstream sustainability in every sector of operations and it is the responsibility of every industry and every individual to contribute towards various sustainability issues / challenges for achieving long term sustainability goals.

Globally, the Information Technology (IT) sector has grown up in multiple folds in a short span of time with substantial contribution to global economy and business. Rapid growth of IT industry is positively contributing to higher growth of infrastructure development (commercial \& residential) and employment generation. But, along with the contribution to economical, industrial and developmental aspects, IT sector is also contributing to increased energy and natural resources consumption, generation of electronic waste (E-Waste) and increased carbon emissions (due to energy consumption and increased business travel activities.) The rapid economic growth and changes in IT sector has made it necessary for the companies to update and monitor their own technological competence. This further leads to additional resource consumption and E-waste generation. With high business growth potential and rising demand, IT sector is going through various major sustainability issues and challenges including high energy consumption, waste management, carbon emissions and human resource management.

To the many fold growth of IT sector in last decade, IT sector SME is also one of the major contributors and the sector is growing continuously. But due to many constrains, IT-SME sector focus is mainly on business development and economic growth to sustain in the highly competitive market by providing different value added, cost effective services and sustainable solution to the clients. Including effective use of cloud computing, which is considered as one of the energy efficient option for the services offered. If we consider the environmental impact for an SME in view of above challenges of IT sector, it is not significant. However, considering the huge number of SMEs operating globally, the cumulative impact is significant and cannot be ignored.

The detailed paper will include analysis of the current scenario of overall IT sector including SMEs of India and Global, in view of their awareness about the sustainability issues, possible measures of improving sustainability contribution and the challenges faced by them for implementation of sustainability measures. Further the paper will also discuss about how the sector can embrace sustainability to reduce environmental impact by energy conservation, carbon footprint reduction along with a goal to achieve Profit Growth and Stakeholder welfare.

Keywords - Information Technology, Sustainability, Energy saving, Data Centers, E-waste etc.

\section{Environmental impact of IT sector including SMEs}

Brundtland Commission of the United Nations on March 20, 1987 quotes: "sustainable development is development that meets the needs of the present without compromising the ability of future generations to meet their own needs."

To analyse the challenge in a wider perspective and reduce environmental impact substantially, it is necessary to evaluate the role of SMEs ${ }^{1}$ for environmental impact and economy. Small Medium sized

\footnotetext{
${ }^{1}$ The report by Organisation for economic co-operation and Development (OECD) mentions that, Small and medium-sized enterprises (SMEs) are non subsidiary, independent firms with limited number of employees. This number varies according to national statistical systems. The most frequent upper limit is 250 employees, as in the
} 
enterprises (SMEs) constitute $90 \%$ of all enterprises globally. More than $95 \%$ of enterprises in OECD countries are SMEs which is employing $60-70 \%$ of workforce in these countries. In year 2013, total SMEs in India are estimated to be 48 (employing $40 \%$ workforce) million whereas China leads with 50 million. This significant number of SME's in major developed and developing countries in different sectors directly contributes to increasing environmental impact caused by their activities.(Enterprises 2011) The report by OECD argues that, the environmental impact of SMEs can be high due to cumulative effects related to a large number of such enterprises. The report further states that SMEs are estimated to generate as much as $60 \%$ of commercial waste and $80 \%$ of pollution $\mathrm{s}$ in England and Wales.(OECD,2012. $)^{2}$ Assuming the same figures for IT sector SME workforce, there is big scope for IT SMEs to contribute for sustainability practices. ${ }^{-}$

It is estimated that about $48 \%$ of the total energy consumed in the industrial sector is from Small and Medium Enterprises (SMEs). By adopting energy conservation solutions $25 \%$ of this can be saved without any major investment. The electricity consumption analysis for a XYZ IT SME is done to promote sustainability. It was observed that average monthly electricity consumption of XYZ Company is around 11,390 units with annual electricity consumption of 136,680 units. The major areas of energy consumption of the company are data centre which includes servers and cooling system, office airconditioners, desktops and personnel computers, UPS(Uninterrupted power supplies) and lighting load. This data is compared to residential electricity consumption in India. The amount of power it takes to run a home will vary considerably based on the way people live, physical house size, appliance standards, electricity prices and access to alternative cooking, heating and cooling fuels and climate conditions. If common household items are considered in India, then

$\begin{array}{lll}\text { An average house uses } \Rightarrow & 900 \mathrm{KWh} / \text { year } \\ \text { XYZ IT SME uses } & \Rightarrow \quad 136,680 \mathrm{KWh} / \text { year. }\end{array}$

According to above comparison, it is observed that the quantity of electricity utilized by XYZ Company is equivalent to electricity consumption of around 150 Indian homes. There is urge to do energy conservation so that the energy can be saved and used for running few homes and also reduce cost to company. ${ }^{4}$ The other aspect is, these huge number of SMEs worldwide create enormous job opportunities and hence contribute to reduce poverty. SMEs are integral part of global economy. But it is hard for business leaders and management to incorporate sustainability initiatives due to the lack of awareness about sustainability challenges, expertise in sustainability, limited finance and human resource.(Approach \& Incentives 2011) .

For growing and contributing IT sector, increasing energy consumption is one of the major sustainability challenges which also substantially contribute for another major sustainability issue of carbon emissions and climate change. Large IT companies are taking various initiatives on Sustainability but more structured and effective approach is required which will cover everyone in the sector including IT SMEs. To address this challenge for SMEs and to gain the maximum environmental benefit along with economic benefit, it is necessary to evaluate the parameters which will reduce environmental impact and will also help to gain profit. There are some services those can be offered to the clients such as cloud computing

European Union. The United States considers SMEs as firms with fewer than 500 employees. However, some countries set the limit at 200 employees.

${ }^{2}$ http://articles.economictimes ${ }^{2}$.indiatimes.com/2013-06-09/news/39834857_1_smes- workforce-small-and-mediumenterprises

${ }^{3}$ There is no exact information available about IT SMEs .Hence, did analysis of data of all sector SMEs and assumed it for IT SMEs.

${ }^{4}$ (Ref : http://shrinkthatfootprint.com/average-household-electricity-consumption 
which is a sustainable solution, beneficial for the company and a value added service offered to the client. Company also can make sure to buy energy efficient equipment, but it is necessary to assess the performance of a SME related to Planet, Profit and People for the sustainable development.

The phrase "the triple bottom line" was first coined in 1994 by John Elkington. The triple bottom line (TBL) aims to measure the financial, social and environmental performance of the corporation over a period of time. Though it is hard to implement, it is a useful entry point for sustainable development since it is simple and easy to grasp. Hence TBL is best suited for SMEs which are not implementing sustainability related initiatives, over other frameworks as this is the first move to initiate sustainability.(Triple \& Line n.d.) $)^{5}$ In view of TBL, the economic variable measures financial gains or profit through company business. Environmental variables represent measurements of natural resources. It refers to sustainable environmental practices. It could incorporate air and water quality, energy consumption, natural resources consumption, solid and toxic waste, and land use/land cover. People or Social variable refers to welfare of employees or labour and community. It includes training and development, more job opportunities. Hence TBL can help to address the sustainability challenges of the company by measuring all parameters of people, planet and profit for sustainable development.

The idea behind using TBL is that business pays attention to all three bottom lines and especially how they influence each other. This can help to achieve long term sustainability benefits.

\section{Opportunities for IT sector in enabling sustainability}

Information technology is not itself a big part of the problem, as it is estimated to contribute only a small percentage of global carbon emissions. IT can be a big part of the solution. Analyst Gartner released the statistics, "IT contributes only $2 \%$ of global carbon emissions, compared with $20 \%$ from agriculture". Globally, contribution of IT to global growth of economy is huge and it has a big share in reducing emissions in other sectors due to its new technology innovations.(Webb 2008),(Jones 2009)

There are different areas where IT has been used for sustainable practices. Following examples shows how IT has the potential to catalyse sustainable enterprises, products.

Dematerialize and Digitize :-Companies or offices are recently using electronic documentation, file storage, intranet for monetary benefit by saving money on warehouse space and thereby reducing environmental impact by reducing use of paper and physical equipment. Teleconferencing is also resulting in reduced carbon footprint by reducing travel. Maximizing Efficiency by computerized control of energy and material use thorough sensors and using energy efficient equipment. ${ }^{6}$

\section{Examples of IT companies implementing sustainability practises.}

Business- IBM Japan has implemented an integrated mobile office system, including 10 satellite offices and working from home. ${ }^{7}$

Health:- Video-conferencing at hospitals in the UK is enhancing training for nurses. This is providing monetary benefit by reducing the cost of training sessions. ${ }^{8}$

Education:- Virtual schools: In rural Colombia there are 28 schools using networked computers for online learning, teacher training and community collaboration. ${ }^{9}$

${ }^{5}$ http://www.economist.com/node/14301663 /

${ }^{6}$ INFORMATION TECHNOLOGY AND SUSTAINABILITY:

ENABLING THE FUTURE by Sahra Girshick, Rajesh Shah and Sissel Waage

The Natural Step, San Francisco, California

${ }^{7}$ http://www.sustainit.org/Files/CaseStudies/PDFcases/ibm.pdf)

${ }^{8}$ :http://www.sustainit.org/Files/CeStudies/PDFcases/oswalds.pdf)

${ }^{9}$ :http://www.sustainit.org/Files/CeStudies/PDFcases/oswalds.pdf) 
But considering the rapid growth and demand of IT products and services and its rapid adoption, Information and communications technology (ICT) companies need to contribute more to sustainability than companies of many other sectors. this $2 \%$ of worldwide emissions of IT industry, is projected to grow under business-as-usual (BAU) conditions at a 6\% compound annual growth rate to 1.4 GTonnes of $\mathrm{CO} 2$ by 2020 from current $0.5 \mathrm{GT}$ Tonnes assuming that the sector will continue to make progress on energy efficiency as it has been doing. It is expected that by 2020 with the population growth in developing countries like China and India the affordability to buy ICT devices will increase. They will account for $60 \%$ of ICTs carbon emission. But Data Center will have larger share in footprint as the need for storage, computing and other IT services will grow. (Webb 2008),(Jones 2009)

It is of great importance that as many enterprises need to initiate sustainability as per their sector requirement and reduce environmental impact by energy conservation measures as it will reduce climate change impact. Climate change and global warming are the major alarming concerns of the world. Reducing consumption of energy is one of the means to reduce emissions and is mitigation for climate change. Presently fossil fuels (Oil, Coal and natural gas) supply humanity with the vast majority of our energy demands, and at a growing rate. Demand of energy is increasing as the population is growing and also usage of IT products, specifically in developing countries like India and China. Smart and practical approaches for energy conservation are needed, as energy, a driver of development, plays a vital role in both fighting poverty and addressing climate change.

\section{Energy Consumption in IT sector}

There is significant and growing role of IT and data centers in the world's consumption of electric energy and carbon footprint. Data center network typically includes: IT equipment such as computing devices (e.g. servers, storage and networking equipment), cooling equipment such as air-conditioning units, power systems such as diesel generators (for backup purposes), uninterruptible power supplies, and supporting infrastructure Hence many companies are adopting sustainable practices known as Green IT which includes Virtualization, Grid computing.. . (Greening of IT,John Lamb, 2009)

Energy expenditures for IT keep increasing. Less than half of the power used by a Data centre is used for its IT equipment and more than half power is utilized in infrastructure including cooling systems, UPS, lighting. The data centre equipment power cost will increase over its capital investment for its useful life.(Back 2008). According to Greenpeace's most recent report, the cloud consumes as much energy as what would be the world's sixth largest country. ${ }^{10}$ Increasing demand for IT services and equipments has led to significant growth in the number of data centers servers during last five years, hence there is rise in the energy used by these servers and the power and cooling infrastructure that supports them. This increase in energy use has a number of important implications: Rise in energy costs for business and government, increased emissions, including greenhouse gases from electricity generation, increased strain on the existing power grid to meet the increased electricity demand and more investment for expansion of data centre due to increased demand. Main sustainability issues that IT companies face in the own organizations, are mainly due to energy consumption related to data centers infrastructure, PC and desktop infrastructure, This energy is increasingly expensive, and if derived from fossil fuels, contributes to climate change.

Energy consumption in IT companies is mainly due to

- Data centers which comprise of the servers of few clients

\footnotetext{
${ }^{10} \mathrm{http}: / / \mathrm{www}$. techrepublic.com/article/how-tech-companies-are-propelling-the-environmental-movement/
} 
- Cooling for Datacentre

- UPS and DG set

- PC and Desktop infrastructure and peripherals, lighting

\section{Other impacts of IT industry}

E waste generation is also one of the major issues causing environmental impact.

Rapid economic growth, urbanization and increasing consumer demand is causing more production and consumption of Electronic and Electrical appliances (EEE).This is leading to generation of more $\mathrm{E}$ waste. E-waste and environmental pollution is a global problem. The United Nations mentions that global ewaste is set to exceed 40 million tons per year. The e-waste is having serious health implications as itnot only pollutes the land-fill but also eventually making its way to agricultural produce and into people. According to a recent report by the BBC, e-waste pollution is causing severe health concerns for millions of people around the world, mostly in the developing nations of Africa, Europe and Asia. The report mentions that approximately 23 percent of deaths in these nations are linked to pollution and other environmental impacts and more than 200 million people worldwide are at risk of exposure to toxic waste. ${ }^{11}$ The waste minimization can be done by using waste minimization techniques and by a Sustainable product design.

Industries are adopting following solutions for waste minimization which includes, Reuse and recovery, volume reduction, sustainable product design includes, use of biodegradable materials for electronic components and peripherals, Use of renewable energy, Green packaging options. The majority of high tech assembly workers, who work with hazardous chemicals, experience serious impacts on their health compared to employees in other sectors. For example, many workers in chip manufacturing are reporting cancer clusters and birth defects. Capacity building and awareness building is very important for e waste management and to avoid serious complications related to health and safety.

\section{Best Practices implemented in IT organizations:}

CAPGEMINI is one of the top five IT services and consulting companies worldwide based in Europe and is headquartered in Paris and France. The Company has focussed on embedding the principles of corporate responsibility and sustainability into its business strategy, processes and ways of working. The main environmental impact is caused by consumption of electricity, gas and oil to light, heat and power to offices and data centers of company. Data centers consumes huge amount of energy as the high level of IT equipment are housed, powered and cooled in data centers. Around $78 \%$ of the electricity used in UK operations is consumed by the data processing centers alone.

Cap Gemini's Smart Energy Management Solutions is a multi-component energy management offering that reduces carbon emissions These solutions implemented by the company is not only addressing the environmental impact but also helping in economic growth. As an outsourcing provider the company is ensuring to do energy conservation through sustainable data centers which is the client's IT estate. Cloud computing is also helping to maximise the efficiency of clients application and to embed sustainability into processes and infrastructure.(Capgemini, 2013). Apple and Facebook have built new data centers that run on $100 \%$ renewable energy, and Google is also keeping the same goal. ${ }^{12}$

\footnotetext{
${ }^{11}$ IMPACT OF ELECTRONIC WASTE LEADING TO ENVIRONMENTAL POLLUTION http://jchps.com/specialissues/Special\%20issue3/03\%20jchps\%20si3\%20Y.Sitaramaiah\%2039-42.pdf

${ }^{12}$ http://www.techrepublic.com/article/how-tech-companies-are-propelling-the-environmental-movement/
} 
Tata Consultancy Services (TCS):- Tata Consultancy Services is an IT services, business solutions, and Business Process Services (BPS) organization that delivers real results to global businesses, with a high level of certainty. It is founded in 1968 as part of the Tata group, headquartered in Mumbai, India and is a public limited company.TCS is actively implementing sustainability initiatives. Tata Group Climate change Policy and TCS Environmental Policy, GHG accounting and mitigation are key elements of the environmental sustainability roadmap (2020) of TCS.TCS' strategy to build 'green' infrastructure and energy efficient IT infrastructure (including data centers) is a key enabler of its environmental sustainability roadmap.TCS is also aware of e-waste generated. E-waste is disposed of through government authorized recyclers. TCS also takes care of social element like working and labour conditions, learning opportunities and career development of employees, health and safety. (TCS, 201516)

\section{Conclusion and Recommendations}

There is significant and growing role of IT and data centers in the world's consumption of electric energy and carbon footprint. IT equipment energy consumption and cooling are related sustainability issues as both require energy, which is increasingly expensive, and, when derived from fossil fuels, contributes to climate change. Hence it is very much necessary to bring innovative energy efficient techniques in this area and further pushthe use of energy efficient equipment and infrastructure. Apart from energy consumption of IT sector, it has a lot of potential to contribute in sustainability practices in other sectors.

E waste generation is also very growing problem of IT sector impacting environment, health. SMEs are, still to a lot extent, only business focused. Sustainability is viewed in terms of only financial sustenance. Government, IT sector and leadership push is required for SMEs to bring into flow, awareness, long term benefit and related actions to solve global sustainability problem. The cumulative environmental impact of SMEs due to energy usage, carbon emissions, resources usage and waste is certainly substantial related to large companies, considering their large number. The SMEs should be focused to solve the larger part of the problem.

Further to above, it is recommended that IT sector big companies and SMEs which are not/less active for promoting sustainability initiatives need to initiate sustainability approach and focus on reducing its environmental impact and thereby reducing energy cost thereby achieving economic growth.

1. Energy conservation being a well proven low hanging fruit, efforts should target for minimizing the energy consumption and carbon footprint. Reduced electricity bill directly contributes to the profits and support for the economic growth. It further includes initiatives for use of renewable energy.

2. Detailed energy consumption analysis should be done based on the company specific data and inputs. Referring to the sustainable best practices provided by CAPGEMINI to the clients, these companiescan also Improve the energy efficiency of IT Data center and mitigate the risk of increasing emissions through data centers The industry best practices needs to be adopted to achieve the goal. Companies needs to present sustainable solutions like cloud computing to more clients. The use of clean energy can reduce the carbon footprint of company and is a cost effective solution to the client.

3. The companies can launch Green IT-Energy Efficiency services to its clients. In order to build reputation for these services, these companies could first undertake greening initiatives in its operations, and then showcase it as a case study to prospective clients. Although the initial cost could be higher, the company can benefit from long-term cost reductions 
4. Disseminating the concept of economic benefits created by improved environmental performance. It is necessary to create awareness related to global and company specific sustainability challenges .amongst employees, clients, and leadership who are the stakeholders.

5. Training and capacity building is required to promote sustainability in organization. Skilled resources needs to be appointed who can train the other employees. Further, the sustainability framework like TBL may be implemented to adopt sustainability.

6. Company can benchmark its own performance against other players in the industry. This can bring substantial push to improve against competition. Further, this can be unique Selling point for the company to present to its customers.

7. E-waste management and minimization can be done by IT companies by following the best practices implemented by big players in the industry.

\section{References}

1. Capgemini, 2013. Corporate Responsibility \& Sustainability Review 2013.

2. OECD frameworks, 2007. Final Report of International Action Research Project Based on research carried out by Dr. Andy Johnston, seconded to the OECD from Forum for the Future , in October 2006 - March 2007. , (October 2006), pp.1-62.

3. OECD, 2007, SMALL BUSINESSES AND ENVIRONMENTAL Review and Possible Application of International Experience in Georgia.

4. Approach, C. \& Incentives, F., 2011. Unlocking Energy Efficiency Market in India' s SME Sector Cluster Approach and Role of ESCOs \& Fiscal Incentives.

5. Back, T., 2008. Energy efficiency and buildings. , pp.1-4. Available at: http://www.indianjournals.com/ijor.aspx?target=ijor:tn\&volume=14\&issue=4\&article=fed [Accessed May 20, 2014].

6. Enterprises, M., 2011. IFC and Small and Medium Enterprises. , pp.1-2.

7. Greening of IT,John Lamb, 2009. http://www.ebook3000.com/The-Greening-of-IT--HowCompanies-Can-Make-a-Difference-for-the-Environment_49257.html

8. Information Technology and Sustainability,Lorenz M Hilty,2008 ,http://books.google.com.ph/books?id=2vlVVfFS_2YC\&printsec=frontcover\&dq=Information+T echnology+and+sustainability\&hl=en\&sa $=X \&$ ei=GWCVU8O-

LMLeoATStYDwDQ\&ved=0CDsQ6AEwAA\#v=onepage\&q=Information\%20Technology\%20a nd $\% 20$ sustainability $\& \mathrm{f}=$ false

9. IT and Sustainability:Enabling the Future, 2002

10. http://c.ymcdn.com/sites/www.productstewardship.us/resource/resmgr/imported/itsi_researchpap er.pdf

11. Jones, T., 2009. IT and Sustainability: Bringing Best Practices to the Business. Economist Intelligence Unit, Oracle. Available http://scholar.google.com/scholar?hl=en\&btnG=Search\&q=intitle:IT+and+sustainability+:+Bring ing+best+practices+to+the+business\#8 [Accessed May 20, 2014]. 
12. TCS,2015-16 http://sites.tcs.com/corporate-sustainability/wp-content/uploads/2016/12/GRI-2016Sustainability-Report.pdf

13. Triple, T. \& Line, B., The Triple Bottom Line : What Is It and How Does It Work ?, pp.4-8.

14. Vishakha Nandanpawar, Sustainability promotion for IT sector Small and Medium scale Enterprise (SME) by reducing Energy and Environmental impact and contributing for economic benefit, submited to CISL, Unversity of Cambridge, UK

15. Webb, M., 2008. SMART 2020: Enabling the low carbon economy in the information age. The Climate Group. London. Available at: http://scholar.google.com/scholar?hl=en\&btnG=Search\&q=intitle:SMART+2020+:+Enabling+th e+low+carbon+economy+in+the+information+age\#0 [Accessed May 20, 2014].

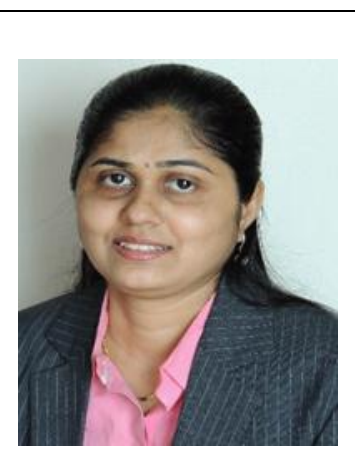

\section{Vishakha Chande Nandanpawar}

Vishakha is an Electronics Engineer with Postgraduate Certificate in Sustainable Business (PCSB) from University of Cambridge (with Cambridge University Scholarship). She received Diploma in Software Testing from SEED InfoTech, India and International Software Testing Certification from International Software Testing Qualification Quality Board (ISTQB).

Vishakha is an IT and Sustainability professional with work experience of more than ten years which includes work experience of more than eighth ears in the area of software testing and academics. Currently she is working as an independent consultant in sustainability area and focusing on sustainability in IT sector. Her past working experience includes her long international stint of more than five years with Capgemini (I) Pvt Ltd, India. Before Capgemini, she worked as software engineer with Kanbay India Ltd. and Synthesis Solutions and worked as Lecturer at High Tech Engineering College, Pune and YCC Engineering College Nagpur.

In view of her special efforts and contribution towards successful execution of various projects of different clients, she received special appreciations major one includes, Capgemini's FS-SBU "Leadership Award of Excellence" for contribution to the project, as a best Team Leader, Certificate of Appreciation' from HSBC, as a client, for outstanding performance and continued contribution to Quality Delivery and Appreciation Award from GE-UK in recognition to valuable contribution to the 'GEMONEY QAT' as a team leader while working on GE project of credit cards. 